\title{
Proposal of Decision Criteria Based on Product Characteristics for WEEE Recycling in Romania: A Managerial Approach
}

\section{Carmen Nadia Ciocoiu}

Faculty of Management, Bucharest University of Economic Studies, Romania

Email: nadia.ciocoiu@man.ase.ro

\section{Irina Eugenia lamandi}

Faculty of International Business and Economics, Bucharest University of Economic Studies, Romania Email: irina.iamandi@rei.ase.ro

\section{Sebastian Madalin Munteanu}

Faculty of Management, Bucharest University of Economic Studies, Romania Email: sebastian.munteanu@ase.ro

\section{Doi:10.5901/ajis.2015.v4n3s1p672}

\begin{abstract}
With growing interest in recovering materials within electrical and electronic equipment at the end of their useful life, there has been an increasing interest in developing decision-making methodologies that determine how to maximize the recycling benefits of end-of life processing. In the case of multi-criteria decision methods, the most complex step is to identify the decision criteria that can be characterized by attributes by decision makers and are relevant to the analysed situation taking into account all impact categories. This study identifies and describes the set of criteria based on product characteristics relevant for recycling in Romania, from the point of view of recyclers. Nineteen criteria were identified and grouped into 3 categories, namely: economic, environmental and technical.
\end{abstract}

Keywords: decision criteria, electrical and electronic equipment, recycling, Romania, WEEE

\section{Introduction}

Over the last twenty years, the number of electrical and electronic equipment (EEE) continues to grow exponentially and the life cycle of the electrical devices is shorter. Waste electrical and electronic equipment (WEEE) has known the most spectacular growth of all waste categories. In Europe, there are over 10 million tonnes of WEEE generated annually and it is expected that, by 2020, this figure will reach 12 million tonnes (European Commission, 2012).

Electrical equipment contains hazardous materials (lead, mercury, cadmium, chromium, phosphorus, barium, beryllium etc.), as well secondary raw materials with economic value (iron, aluminium, copper, plastic, glass etc.) (Ciocoiu et al., 2012).

One way of preventing hazardous effects of EEE and to prevent depletion of resources is to treat them in a proper way and to recycle valuable parts and materials. On the other hand, the increasing global competition for primary raw materials and the increasing price volatility will enforce companies to pay more attention to recycling activities.

Recycling represents an important issue in WEEE legislation in European Union. The new WEEE Directive of European Union (Directive 2012/19/EU) has set new target thresholds for the collection, treatment and recovery, some of these levels being applied beginning with 2015.

In Romania, waste electrical and electronic equipment recycling market is growing every year. When we talk about recycling in Romania we are referring to waste treatment operations that are defined, under Romanian law, as recovery or disposal operations, including preparation prior to recovery or disposal.

If in terms of treatment and recovery Romania falls in line with the standards imposed by both the old and the new EU WEEE Directive (Directive 2002/96/EC and Directive 2012/19/EU), the WEEE regulations concerning the collection represent a threat, but also an important challenge for the WEEE management system in Romania (Rudăreanu et al., 2015).

Regarding the Romanian effort for WEEE collection and treatment, it is important to mention the most significant 
company specialized for these services: GreenWEEE International. This company is located in Buzau County (approximately $120 \mathrm{~km}$ far from Bucharest) and it started the activity in 2009. The company has the largest capacity in Romania for collecting and processing of the WEEE (50.000 tonnes of WEEE per year, with an initial investment of 10 million euro) (www.greenweee.ro).

The first part of the paper presents the most important studies about WEEE recycling criteria, then the objective and the methodology of the research, as well as the results and conclusions are emphasized.

\section{Literature Review}

The issue of selecting certain products or categories of WEEE - according to their characteristics - in order to treat or recycle them by the specialized organizations was partially approached in the external scientific literature, but dedicated studies were not conducted for the Romanian case.

Kiritsis et al. (2005) present a multicriteria-based methodology to evaluate the end of life product treatment options with regard to environmental, economic and social criteria.

lakovou et al. (2009, p. 331) propose a multicriteria selection matrix for recycling WEEE, that includes the following elements: residual/market value of the components, environmental costs of the product, weight of the product, amount of the same component in the product, ease and duration of the dismantling process.

Kara (2011) mentions some hindrances that make recycling challenging for current manufactured products. One of these is the difficulty to gain all the necessary information to plan for the recycling evaluation. The decision to invest in WEEE recycling is complex and it must take into account many different criteria.

Of an even more recent date, Kim et al. (2013, p. 945) recommend a set of seven criteria for selecting WEEE to be included into the system of compulsory recycling in Korea: high rate of waste generation (waste volume or emission rate); low recycling costs or benefits resulted from recycling (availability of appropriate recycling technology, high content of valuable metals and potential of recovering them, workable collection system); similarity with other products currently included in the extended responsibility of the producer (ERP); similarity with current plastic products disposed for free in Korea according to the present legislation. Other factors proposed by Kim et al. (2013, pp. 942-944) to be taken into account are the following: potential economic value; presence of toxic chemicals; potential impact of EEE on the environment.

\section{Objective and Methodology of Research}

Taking into account the above mentioned aspects, our purpose is to develop a set of criteria for analysing the relevant WEEE to be recycled in Romania, by taking into account the characteristics of the considered categories of products. This represents the first step in developing a multi-criteria decision making method in order to help the decision makers to select the most feasible products (or categories) to be recycled.

Every criterion was selected and analysed in relation with the availability of product-related information data.

The study was conducted in two phases. In the first phase, information from several sources was reviewed and analysed: legislation and policy documents, statistical data from Eurostat and Romanian National Statistics Institute, research studies, articles and conference papers, reports and other public and internal documents published by WEEE national organizations. A main source of information was represented by the documents published by the Romanian Agency for the Environmental Protection (ANPM).

In the second phase, discussions with experts were held in order to select the relevant criteria and to test their practical utility.

Thus, the consulted experts think that the analysis could be limited, for now, just to WEEE treatment operations, given that the technical European model of operators in the field does not exceed (with few exceptions) the removal of hazardous, recoverable or recyclable components. The same experts commented that most of the operations regarding recycling, recovering or reusing the fractions resulted from WEEE treatment are developed by specialized companies from inside or outside EU.

\section{Results and Discussions}

The proposed criteria for the economic operators that treat, recover (exploit) and recycle the WEEE are structured into three main domains: economic, environmental and technical criteria. 


\section{Economic Criteria of WEEE:}

\subsection{Economic value resulted from the treatment, recovery and recycle of WEEE:}

One example for quantifying the revenues resulted from WEEE management in Romania is presented in ICPE (2006), as follows: getting revenues by recovering the components (ferrous, non-ferrous, copper and alloys, plastic materials) resulted from WEEE management; identifying the annual quantities that may be recovered for each category of WEEE components; identifying the market prices (RON/kg) for recovering the WEEE components for each category of products; determining the annual revenues (RON) that may be obtained from the recovering activity for each category of WEEE components.

\subsection{Demand on the second-hand market for the components resulted from the dismantling or recycling of WEEE:}

The components resulted from the dismantling or recycling of WEEE in EU may be recovered with cost savings and benefits in economic and environmental terms, by protecting and/or better using the resources. In this regard, "the efficient use of resources and the retrieval of valuable secondary raw materials" is one of the main objectives of the Directive 2012/19/EU (paragraph (6)). Moreover, this point of view is also supported by the economic operators (see the GreenWEEE website, 2015). On the other hand, following broad consultations with experts in the field, they confirmed that the treatment of WEEE also generates complex fractions, with negative market value, such as: glass from cathode ray tubes, electrolytic capacitors, mixture of hazardous materials etc.

\subsection{Amount of similar or identical EEE traded on the market:}

For a comparative analysis in the European context, the amount of EEE put on the Romanian market - total by years (2006-2012) and for the 10 categories of EEE - is available on the Eurostat (2015) website.

\subsection{Competition between categories of WEEE recyclers:}

According to the opinion of the experts, there are no stricto sensu recyclers of WEEE in Romania, and this category of economic operators could be divided by the type of developed activities: collection, treatment, collection of fractions resulted from treatment, recycling of fractions of ferrous and non-ferrous metals, disposal of fractions with hazardous content. Thus, by "recyclers" we refer to "economic operators involved in WEEE management" or "economic operators involved in WEEE treatment".

\subsection{Value of the recycling investment or cost of technology used for treating or recycling WEEE:}

This criterion is fundamentally determined by the efficiency of the economic operators in the field for complying with their business operations. As examples, methods for determining the costs of establishing and operating a WEEE collection point, determining the costs of establishing and operating a WEEE treatment point, determining the costs of advertising campaigns and public awareness in Romania are presented in ICPE (2006).

\subsection{Renewal rate for the EEE categories to be recycled:}

There are only partial analyses in Romania (in terms of time and space) regarding the way in which the population uses the different categories of EEE, and these studies have been financed by the local public authorities or by companies with direct interests in the field. The collected and used information in the respective studies rather focus on certain products and not on the 10 categories of EEE identified at European level.

\section{Environmental Criteria of WEEE}

\subsection{Volume (weight) of collected WEEE:}

There are complete series of data on the Eurostat (2015) website regarding the WEEE management in EU countries: 
amount of waste collected on the Romanian market, total by years (2006-2012) and for the 10 EEE categories; amount of waste collected from households; amount of waste collected from other sources. The distribution of the amount of WEEE collected on the Romanian market - by years (2006-2013) and for the 10 categories of EEE - is available on the ANPM (2015) website, while the EU annual collecting target of $4 \mathrm{~kg} / \mathrm{capita}$ was not achieved in Romania. At national level, regarding the annual collection rate, a number of exemptions from the Directive 2012/19/EU may be applied until, at the latest, 14 August 2021 (Directive 2012/19/EU, Art. 7).

\subsection{Volume (weight) of treated WEEE:}

The total amount of treated WEEE is a sum aggregated from the following three elements: WEEE treated in the respective EU member state, WEEE treated in another EU member state and WEEE treated outside EU. For Romania, different data series are available on the Eurostat (2015) website: amount of WEEE treated in the member state, total by years (2006-2012) and for the 10 EEE categories; amount of WEEE treated in another EU member state; amount of WEEE treated outside EU; amount of reused WEEE; amount of recovered WEEE; total amount of recycled and reused WEEE.

\subsection{Quantity of disposed waste resulted from recycling and/or recovering of WEEE:}

When determining this indicator, the total amount of recycled and reused WEEE on the Romanian market may be used (by years and for the $10 \mathrm{EEE}$ categories), as well as the recovering and/or recycling rates for WEEE in Romania.

\subsection{Real recycling rate of WEEE:}

According to Government Emergency Ordinance (GEO) No. 5/2015, Appendix 9, the recovering and recycling of WEEE are differently targeted, with different envisaged values for the WEEE categories, before and after 14 August 2015. Information regarding the quantification of the real recycling rate of e-waste are available on the Eurostat (2015) website.

\subsection{Potential of WEEE pollution (a) - toxic and hazardous waste resulted from recycling:}

The potential of WEEE to pollute was analysed by taking into account two main categories of factors that could fundamentally and negatively impact the external environment: the toxic and hazardous waste resulted from recycling, but also the negative externalities resulted from incineration (the incineration of WEEE is the second best option when they cannot be recovered, reused, recycled or valued in another way than by energy generation).

\subsection{Potential of WEEE pollution (b) - toxic and hazardous waste resulted from incineration:}

Regarding the second component of the WEEE potential of pollution, a correlation could be established with the weight of recovered, reused and recycled WEEE, assuming that the percent of not recovered / reused / recycled WEEE will be disposed by incineration or simple storage.

\subsection{Energy consumption per unit of recycled WEEE:}

Although information regarding the energy consumption per unit of recycled WEEE is not public or centralized, the consulted experts recommend their gathering from specialized economic operators carrying out treatment activities of WEEE. In addition, this type of consumption - like the resource consumption for the economic processes - essentially depends on the efficiency of the respective economic operators (treatment facilities or recycling units).

\subsection{Content of hazardous substances for the environment and human health of the WEEE to be treated and recycled:}

The issue of hazardous and/or harmful substances included in the WEEE is of current interest at EU level and it is approached in a centralized way as one of the main challenges in the field (see the Directive 2012/19/EU, paragraphs (5) and (15)). 


\section{Technical Criteria of WEEE}

\subsection{Size of WEEE to be recycled:}

Information about the categories of EEEE (and, implicitly, about their dimensions) are also available in the Directive 2012/19/EU (Appendixes I-IV) and the GD No. 1037/2010 (Appendixes 1A-1B). The average weight of EEE is essentially influenced by the constant trend of reducing the specific sizes and weights due to the technological developments estimated at global level.

\subsection{Homogeneity of the components of WEEE to be recycled:}

When a product has more components of the same type or it is more homogenous in terms of composition, its recycling is more profitable for the economic operators because their investments are more efficient. The amount of recovered fractions of WEEE resulted from dismantling cover at least the following components: glass, ferrous and nonferrous metals, copper and alloys, plastic, and other (PCB circuits, rubber, wood, ceramics etc.).

\subsection{Ease of dismantling and/or recycling of WEEE to be recycled:}

In a similar way, the ease of recycling the products and the secondary valuable materials in their composition is a criterion that assures the operational economic viability for the companies that treat or recycle WEEE. According to the consulted experts, the treating technology of WEEE could be divided into three main categories: manual, mechanical and mixed treatment.

\subsection{Quantity of valuable metals resulted from WEEE recycling:}

Both the specialized literature (e.g. Kim et al., 2013) and practical evidence support the recycling of WEEE also for the extraction of valuable metals (e.g. silver, platinum, gold, and palladium) from certain components, resulting financial benefits for the economic operators in the field.

\subsection{Recovering/Recycling rate relative to the average weight of WEEE to be recycled:}

At EU centralized level, the minimum objectives for WEEE recovering and recycling corresponding to each category of waste, before and after 14 August 2015, are detailed in Appendix V of the Directive 2012/19/EU. For Romania, after the entry into force of GEO 5/2015 on WEEE, the necessary national recovery and recycling rates are stipulated in Appendix 9 of the mentioned document.

\section{Conclusions}

This economic sector of waste treatment and recycling has a great potential to contribute to job creation and investment recovery through an integrated approach at national level, taking into account an increase in the rate of absorption of European funds allocated to environmental investments. The revisions of national and European legislation regarding WEEE represent a factor that may reinforce the interest for WEEE recycling in Romania.

Although the choice of electrical and electronic products to be recycled depends very much on the technology used (manual, mechanized, mixed), their characteristics may influence the effectiveness of recycling. Developing a multicriteria decision-making method that take into account the variety of product characteristics can help economic agents intending to engage in recycling activities. Proposing a set of criteria based on particularities of WEEE management system in Romania is the first step in creating the decision-making method. Although the set of criteria is designated for Romania it can be applied (totally or partially) in any country that has a similar management system.

Next step of the research consists in developing and testing the multicriteria decision-making method for WEEE recycling by taking into account different products and categories of EEE. 


\section{Acknowledgements}

This work was supported by MEN - UEFISCDI, Joint Applied Research Projects programme, project number PN-II-PTPCCA-2013-4-1400, contract 320/2014.

\section{References}

Agenția Națională pentru Protecția Mediului [National Agency for Environmental Protection] (ANPM), 2015. Waste of electrical and electronic equipment. Available online at: http://www.anpm.ro/deseuri-de-echipamente-electrice-si-electronice [Accessed March 6, 2015].

Ciocoiu, C.N. (Editor), 2012. Modern Approaches in Exploring the Link between Digital Economy and E-Waste Management. Bucuresti: Editura ASE.

European Commission, 2003. Directive 2002/95/EC of the European Parliament and of the Council of 27 January 2003 on the restriction of the use of certain hazardous substances in electrical and electronic equipment. Official Journal of the European Union, L 37/19, 13.02.2003, Brussels, Belgium. Available online at: http://eur-lex.europa.eu/legal-content/EN/TXT/PDF/?uri=CELEX:320 02L0095\&from=EN [Accessed February 20, 2015].

European Commission, 2003. Directive 2002/96/EC of the European Parliament and of the Council of 27 January 2003 on waste electrical and electronic equipment (WEEE). Official Journal of the European Union, L 37/24, 13.02.2003, Brussels, Belgium. Available online at: http://eur-lex.europa.eu/resource.html?uri=cellar:ac89e64f-a4a5-4c13-8d96-1fd1d6bcaa49.0004.02/DOC_1\& format=PDF [Accessed February 20, 2015].

European Commission, 2011. Directive 2011/65/EU of the European Parliament and of the Council of 8 June 2011 on the restriction of the use of certain hazardous substances in electrical and electronic equipment (recast). Official Journal of the European Union, $\mathrm{L}$ 174/88, 01.07.2011, Brussels, Belgium. Available online at: http://eur-lex.europa.eu/legal-content/EN/TXT/PDF/?uri=CELEX:320 11L0065\&from=EN [Accessed February 20, 2015].

European Commission, 2012. Directive 2012/19/EU of the European Parliament and of the Council of 4 July 2012 on waste electrical and electronic equipment (WEEE) (recast). Official Journal of the European Union, L 197/38, 24.07.2012, Brussels, Belgium. Available online at: http://eur-lex.europa.eu/legal-content/EN/TXT/PDF/?uri=CELEX:32012L0019\&from=EN [Accessed February 20, 2015].

European Commission, 2015. Waste Electrical \& Electronic Equipment (WEEE). Available online at: http:/lec.europa.eu/environment/ waste/weee/index_en.htm [Accessed March 6, 2015].

European Commission, Eurostat, 2015. Waste Electrical and Electronic Equipment (WEEE). Available online at: http://ec.europa.eu/ eurostat/c/portal//ayout?p___id=664648\&p_v_I_s_g_id=0, http://ec.europa.eu/eurostat/data/database?p_auth=YIzVEtRG\&p_p_id =estatsearchportlet_WAR_estatsearchportlet\&p_p_lifecycle=1\&p_p_state=maximized\&p_p_mode=view\&_estatsearchportlet_W AR_estatsearchportlet_action=search\&text=WEEE [Accessed March 8, 2015].

GreenWEEE, 2015. GreenWEEE Electric \& Electronic Equipment Recycling. Available online at: http://www.greenweee.ro/ [Accessed March 10, 2015].

Guvernul României [Romanian Government], 2010. Decision No. 1037 of 13 October 2010 on waste electrical and electronic equipment. Published in Monitorul Oficial [The Official Gazette], No. 728 of 2 November 2010, Bucharest, Romania. Available online at: http://www.mmediu.ro/beta/wp-content/uploads/2012/05/2012-05-18_hg_1037_2010.pdf [Accessed March 3, 2015].

Guvernul României [Romanian Government], 2015. Emergency Ordinance No. 5 of 2 April 2015 on waste electrical and electronic equipment. Published in Monitorul Oficial [The Official Gazette], No. 253 of 16 April 2015, Bucharest, Romania. Available online at: http://www.anpm.ro/documents/12220/2043942/OUG+5_2015+privind+de\%C5\%9Feurile+de+echipamente+electrice+\%C5 \%9Fi+electronice.pdf/4c3d437b-e81b-4745-9e99-9f2ef710f613 [Accessed May 20, 2015].

lakovou, E., Moussiopoulos, N., Xanthopoulos, A., Achillas, Ch., Michailidis, N., Chatzipanagioti, M., Koroneos, C., Bouzakis, K.-D., Kikis, V., 2009. A methodological framework for end-of-life management of electronic products. Resources, Conservation and Recycling, 53(6), pp. 329-339.

Institutul de Cercetări și Proiectări Electrotehnice [ICPE Research Organization] (ICPE), 2006. Study for determining the costs of waste management of electrical and electronic equipment and determining the required number of collection points in Romania, Contract No. 362/2006, Contracting Authority: Ministry of Environment and Water Management. Available online at: http://www.greenweee.ro/images/stories/legislatie/studii/30 studiu costuri gestionare DEEE 3.pdf [Accessed March 10, 2015].

Kara, S.S., 2011. Evaluation of outsourcing companies of waste electrical and electronic equipment recycling. International Journal of Environment Science and Technology, 8(2), pp. 291-304.

Kim, M., Jang, Y.-C., Lee, S., 2013. Application of Delphi-AHP methods to select the priorities of WEEE for recycling in a waste management decision-making tool. Journal of Environmental Management, 128 (15 October 2013), pp. 941-948.

Kiritsis, D., Bufardi, A., Xirouchakis, P., 2005. Multi-criteria decision aid for product end of life options selection. In: Proceedings of the Institute of Electrical and Electronics Engineers (IEEE) International Symposium on Electronics and the Environment in 2005, pp. 48-53.

Rudăreanu, C., Popescu, M.-L., Ciocoiu, C.N., Colesca, S.E., 2015. A SWOT analysis of the waste electrical and electronic equipment management in Romania. In: Soliman K. (editor), Proceedings of the 25th International Business Information Management 
Association (IBIMA) Conference on Innovation Vision 2020: From Regional Development Sustainability to Global Economic Growth, May 7-8, 2015, Amsterdam, Netherlands, pp. 1612-1622. 